\title{
Selective Short- and Long-Term Effects of Serotonin, Small Cardioactive Peptide, and Tetanic Stimulation on Sensorimotor Synapses of Aplysia in Culture
}

\author{
Samuel Schacher, ${ }^{1}$ PierGiorgio Montarolo, ${ }^{1,2}$ and Eric R. Kandel ${ }^{1,2}$ \\ ${ }^{1}$ Center for Neurobiology and Behavior, and ${ }^{2}$ New York State Psychiatric Institute, Howard Hughes Medical Institute, \\ Columbia University College of Physicians and Surgeons, New York, New York 10032
}

\begin{abstract}
Synapses between the sensory and motor cells of Aplysia can be enhanced by heterosynaptic or homosynaptic stimulation. We have used the isolated sensorimotor synapse of Aplysia in cell culture to explore short- and long-term heterosynaptic facilitation produced by 2 facilitatory transmitters and compared these to homosynaptic facilitation produced by posttetanic potentiation. We found that brief application of 5-HT or small cardioactive peptide (SCP) evokes comparable short-lasting enhancement of nondepressed sensorimotor synapses. The effect evoked by SCP diverges from that of 5-HT when the sensorimotor synapse is first depressed by low-frequency homosynaptic stimulation. Whereas 5-HT facilitates sensorimotor synapses whether or not they are depressed, SCP has little or no effect on synapses that have been depressed by more than $75 \%$. The 2 transmitters also differ in producing long-term facilitation. Whereas repeated applications of 5-HT evoke longterm facilitation of the synapses, SCP applications do not. To determine whether these failures to facilitate could be overcome by increasing levels of CAMP, we applied SCP in the presence of phosphodiesterase inhibitors, which resulted in SCP evoking both short- and long-term changes comparable to that of 5-HT. Homosynaptic facilitation by posttetanic potentiation differed from heterosynaptic facilitation in that tetanic stimulation failed to evoke long-lasting changes in the synapse. These results support recent findings that 5-HT is a critical neuromodulator in behavioral sensitization and dishabituation and suggest that critical levels of CAMP may be required for long- and short-term facilitation of depressed synapses. In addition, the selective action of 5-HT in evoking long-term facilitation suggests that long-term change of this identified synapse may require the activity of specific neuromodulatory pathways.
\end{abstract}

The gill and siphon withdrawal reflex of Aplysia can undergo short- and long-term forms of nonassociative and associative behavioral enhancement. A single noxious stimulus to the body surface can evoke dishabituation or sensitization lasting minutes

Received Mar. 6, 1990; revised May 18, 1990; accepted May 23, 1990.

This work was supported by NIH grant GM 32099 (S.S. and P.G.M.) and by the Howard Hughes Medical Institute (P.G.M. and E.R.K.). We thank L. Eliot, D. Glanzman, and R. Hawkins for their comments and R. Woolley for his technical assistance.

Correspondence should be addressed to Samuel Schacher, Ph.D., Center for Neurobiology and Behavior, Columbia University College of Physicians and Surgeons, 722 West 168th Street, New York, NY 10032.

Copyright $\odot 1990$ Society for Neuroscience $0270-6474 / 90 / 103286-09 \$ 03.00 / 0$ to hours (Pinsker et al., 1970; Carew et al., 1971; Frost et al., 1985; Marcus et al., 1988), whereas repeated stimuli produce behavioral sensitization lasting days to weeks (Pinsker et al., 1973; Frost et al., 1985). Studies on the cellular correlates of these behavioral changes indicate that all are accompanied by an increase in the efficacy of the sensory neuron synapses (Castellucci et al., 1970; Castellucci and Kandel, 1976; Hawkins et al., 1983; Walters and Byrne, 1983; Frost et al., 1985). Several lines of evidence suggest that this facilitation of sensory neuron synapses is mediated by the activation of heterosynaptic pathways and the release of the facilitatory neurotransmitter 5-HT. Sensitizing stimuli increase the firing rate of identified serotonergic cells in the cerebral ganglion, which evokes short-lasting facilitation of sensorimotor synapses (Hawkins, 1989; Mackey et al., 1989). Bath application of 5-HT can simulate the cellular effects evoked by sensitizing stimuli (Brunelli et al., 1976; Castellucci and Kandel, 1976; Klein and Kandel, 1978; Klein et al., 1986). The key role of 5-HT in mediating the effects of sensitizing stimuli is also supported by pharmacological studies. Depletion of 5-HT with injections of the neurotoxin 5,7-dihydroxytryptamine reduces significantly behavioral dishabituation of the reflex (Glanzman et al., 1989). In addition to its role in short-term changes, 5-HT may also play an important role in the long-term enhancement of this synapse that accompanies long-term sensitization. Repeated applications of 5-HT evoke long-lasting enhancement of sensorimotor synapses reconstituted in dissociated cell culture (Montarolo et al., 1986; Dale et al., 1988), including the structural changes in the sensory neurons (Glanzman et al., 1990) found in the intact nervous system of long-term sensitized animals (Bailey and Chen, 1983, $1988 \mathrm{a}, \mathrm{b})$.

Other neuromodulators besides 5-HT, however, can also enhance the synapses between sensory and motor cells and may be involved in aspects of either short- or long-term dishabituation, sensitization, or associative conditioning of the reflex. Sensitizing stimuli that activate the serotonergic cells also activate the identified L29 cells in the abdominal ganglion. The L29 cells, whose transmitter is not known, can directly facilitate sensorimotor synapses both in vivo and in vitro (Hawkins et al., 1981; Hawkins and Schacher, 1989). In addition, the small cardioactive peptides $\left(\mathrm{SCP}_{\mathrm{A}}\right.$ and $\left.\mathrm{SCP}_{\mathrm{B}}\right)$ can produce short-lasting changes when applied directly to the intact abdominal ganglion (Abrams et al., 1984). Because both 5-HT and SCP enhance levels of cAMP in sensory cells (Bernier et al., 1982; Abrams ct al., 1984; Occor and Byrne, 1985), and because increased levels of cAMP accompany short- and long-term sensitization 
(Bernier et al., 1982; Scholz and Byrne, 1988) and appear to be critical for producing short- and long-term facilitation (Brunelli et al., 1976; Castellucci et al., 1980; Schacher et al., 1988; Braha et al., 1990), one might expect both transmitters to have similar effects.

To determine whether these 2 neuromodulators evoke similar short- and long-term enhancement of sensory neuron synapses, we examined the consequences of brief bath applications of 5-HT or SCP on the sensorimotor synapse reconstituted in cell culture. We found that both 5-HT and SCP evoked short-term facilitation when applied to synapses that were not depressed. Unlike 5-HT, however, SCP failed to evoke short-term facilitation when the synapse was first depressed by low-frequency homosynaptic stimulation of the sensory cell. In addition, SCP also failed to evoke long-term facilitation with repeated applications. However, the lack of responses to SCP can be overcome by applying the transmitter in the presence of phosphodiesterase inhibitors such as isobutyl methyl xanthine (IBMX). These results are consistent with the idea that of the transmitters capable of producing short-term facilitation, 5-HT may be of particular importance in mediating long-term synaptic facilitation associated with behavioral sensitization of the gill-withdrawal reflex as well as for short-term dishabituation. In addition, the failure of homosynaptic facilitation to evoke long-lasting changes in the synapse parallel those found for long-term synaptic depression (Montarolo et al., 1988) and suggest that long-term modulation of this synapse may require the actions of specific neuromodulators. Some of these results have been reported in abstract form (Schacher and Montarolo, 1988).

\section{Materials and Methods}

Dissociated cell culture. The cell culture techniques and media used to isolate and maintain identified neurons of Aplysia have been described (Schacher and Proshansky, 1983; Schacher, 1985; Rayport and Schacher, 1986). Culture medium for maintaining the cells, and perfusion medium used during electrophysiological recording and experimental procedures were supplemented with penicillin $(50$ units $/ \mathrm{ml})$ and streptomycin $(50 \mu \mathrm{g} / \mathrm{ml})$. Each dish contained siphon sensory neurons isolated from abdominal ganglia of adult animals ( $80-120 \mathrm{gm})$ cocultured with a single gill and siphon motor cell L7 (Fig. 1) isolated from abdominal ganglia of juvenile animals (1-3 gm). All animals were raised in the laboratory at the Howard Hughes Medical Institute mariculture facility. Cultures were maintained for 4-6 d at $18^{\circ}$.

Electrophysiology and synaptic potential measurements. The stimulation and recording techniques have been described (Dale et al., 1988; Montarolo et al., 1988). The motor cell L7 was impaled intracellularly with a glass microelectrode $(15-25 \mathrm{~m} \Omega)$ containing $2.0 \mathrm{M} \mathrm{KCl}$ and held at a potential of $-30 \mathrm{mV}$ below the resting levels (range of -45 to -58 $\mathrm{mV}$ ). EPSPs were evoked in L7 by stimulating each sensory cell with a brief $(0.2-0.5 \mathrm{msec})$ depolarizing pulse using an extracellular electrode filled with perfusion medium. The initial EPSP amplitudes ranged from 5 to $40 \mathrm{mV}$. To produce homosynaptic depression, sensory cells were given a single stimulus every $30 \mathrm{sec}$. Homosynaptic (posttetanic potentiation) facilitation was produced when sensory cells were stimulated tetanically at 5,10 or $20 \mathrm{~Hz}$ for $2 \mathrm{sec}$, or $20 \mathrm{~Hz}$ for $4 \mathrm{sec}$ with the same extracellular electrode. Stimulus strength was increased by $10-20 \%$ above threshold to insure a 1:1 correspondence between sensory cell stimulus and evoked EPSPs in L7. In pilot experiments we found that the $20 \mathrm{~Hz}$ tetanus for $2 \mathrm{sec}$ evoked the largest facilitation measured 1 min after the tetanus (data not shown). During the recording, cultures were perfused at a rate of $1.5 \mathrm{ml} / \mathrm{min}$ (bath volume, $3.0 \mathrm{ml}$ ) at $18-19^{\circ}$ with perfusion medium, a 1:1 mixture of Leibovitz-15 (Flow Laboratories) and artificial sea water (Instant Ocean) supplemented with $5 \%$ sterile filtered Aplysia hemolymph, pH 7.6. Results were stored on a 4-channcl tape recorder (Hewlett-Packard), and records were made with a Gould pen recorder.

Application of neuromodulators. Neurotransmitter modulators were applied to cells during continuous perfusion by a brief (1-2 sec) puff of
$5 \mu \mathrm{l}$ from a $50 \mu \mathrm{l}$ Hamilton syringe with its tip placed upstream (about $150 \mu \mathrm{m}$ ) and above (about $300 \mu \mathrm{m}$ ) the cells. In pilot experiments, we first determined the concentrations of each neuromodulator that gave a maximal level of facilitation at $1 \mathrm{~min}$ after treatment. We used transmitter concentrations of $5,25,50$ and $100 \mu \mathrm{M}$ (data not shown). The 5 $\mu \mathrm{l}$ of perfusion medium contained final concentrations of either $50 \mu \mathrm{M}$ 5-HT (Sigma), $50 \mu \mathrm{M} \mathrm{SCP}$ or $\mathrm{SCP}_{\mathrm{B}}$ (Molecular Probes), $50 \mu \mathrm{M} \mathrm{SCP}$ plus $\mathrm{SCP}_{\mathrm{B}}$, or $50 \mu \mathrm{M} \mathrm{SCP} \mathrm{B}_{\mathrm{B}}$ plus $25 \mu \mathrm{M} 5-\mathrm{HT}$, and was prepared just prior to each application. The 2 forms of SCP evoked similar short- and longterm changes. We therefore used $\mathrm{SCP}_{\mathrm{B}}$ in all the experiments.

Short-term plasticity. Cultures consisted of one sensory cell and L7. To measure facilitation of nondepressed synapses, the initial amplitude of the EPSP was measured by a single stimulus to each sensory cell 10 min before application of control solution, SCP or $5-\mathrm{HT}$, or a $2 \mathrm{sec}$ tetanus to the sensory cell. The EPSP amplitude was measured 1, 5, and $10 \mathrm{~min}$ after treatment. Both transmitters evoked a transient depolarization of $3-10 \mathrm{mV}$ in $\mathrm{L} 7$ (when hyperpolarized $30 \mathrm{mV}$ below its resting potential) lasting $10-20 \mathrm{sec}$.

To examine facilitation of depressed synapses, sensory cells were stimulated at 30 -sec intervals starting $10 \mathrm{~min}$ after measuring the initial EPSP amplitude. Transmitter or control applications, or tetanus, were given when the EPSP was depressed to $20-25 \%$ of the initial amplitude (10-20 stimuli). IBMX (100 $\mu \mathrm{M}$; Sigma) was added to the perfusion medium for some cultures immediately after the test stimulus and was present during the entire stimulation procedure. The rate of homosynaptic depression was not altered by the presence of IBMX. Following treatments, cells were given up to 5 additional stimuli at $30 \mathrm{sec}$ intervals to determine the degree of facilitation.

Long-term facilitation. Cultures contained 1 or 2 sensory cells and one L7. When both sensory cells formed synapses, the sum of their EPSPs on each day was used to determine percent change in EPSP amplitude. Beginning $10 \mathrm{~min}$ after measuring the initial EPSP amplitude, 1-2-sec puffs of 5-HT or SCP were applied 4 times at 20-min intervals, or sensory cells were given a 2 -sec tetanus 4 times at 20-min intervals. Some cultures were perfused with $100 \mu \mathrm{M}$ IBMX after measuring the initial EPSP. After the last treatment, cultures were rinsed with culture medium, placed back into the incubator, and the EPSP amplitude reexamined $24 \mathrm{hr}$ later. A comparison of the resting potentials of $L 7$ recorded on the second day to those measured on the first showed no significant difference with treatments (mean change of -4 to $-7 \%$ for all control and experimental groups).

Analysis of data. All data in the text and figures are presented as mean percent change \pm SEM (unless specified) in the LPSP measured in L7 normalized to the pre-treatment baseline. The baseline in Figure 3 is normalized to the average of the last 2 depressed EPSPs before treatment. This baseline is compared to the average of the 2 EPSPs measured after the various treatments. For the results shown in Figures 2 and 3, a 2-factor analysis of variance (repeated measures) was used to test for overall significance. For Figure 2, multiple $t$-tests (1-tailed) for planned comparisons corrected for the 2-factor interaction error were used to test for significance of treatment means to the control mean (pre-hoc) at the various time points. These tests were used because the results matched the predicted changes. The Dunnett's $t$-tests (2-tailed) for multiple comparisons of experimental means to the control mean (posthoc) were used in Figure 3, since the results did not match the predicted changes. A 1-factor analysis of variance and Dunnett's $t$-tests were used in Figure 4 to measure significance of the long-term changes produced by the various treatments. As indicated in the text, either paired or unpaired $t$-tests were used for the remaining comparisons.

\section{Results}

Both 5-HT and SCP evoke short-term facilitation of nondepressed synapses, but only 5-HT facilitates

depressed synapses

Previous studies on the intact nervous system of Aplysia demonstrated that synapses between sensory and motor cells can be facilitated by application of 5-HT (Brunelli et al., 1976) or SCP (Abrams et al., 1984). Recently, examination of the facilitation evoked by $5-\mathrm{HT}$ indicated that at least 2 distinct processes can be activated by 5-HT. The contribution of each process to synapse enhancement depends on the prior stimulus history of the sensory cell, that is, whether or not the synapse is first depressed 
Figure 1. Phase-contrast light micrograph of 5-d-old culture containing motor cell (L7) and 2 sensory cells (SN1 and SN2). The structure emerging from the cell body of L7 and lying between the 2 sensory neuron cell bodies is the initial segment of the axon of L7 that was attached to $\mathrm{L} 7$ at plating of the cells. The other neurites have regenerated during the $5 \mathrm{~d}$ of culture. Scale bar, 40 $\mu \mathrm{m}$.

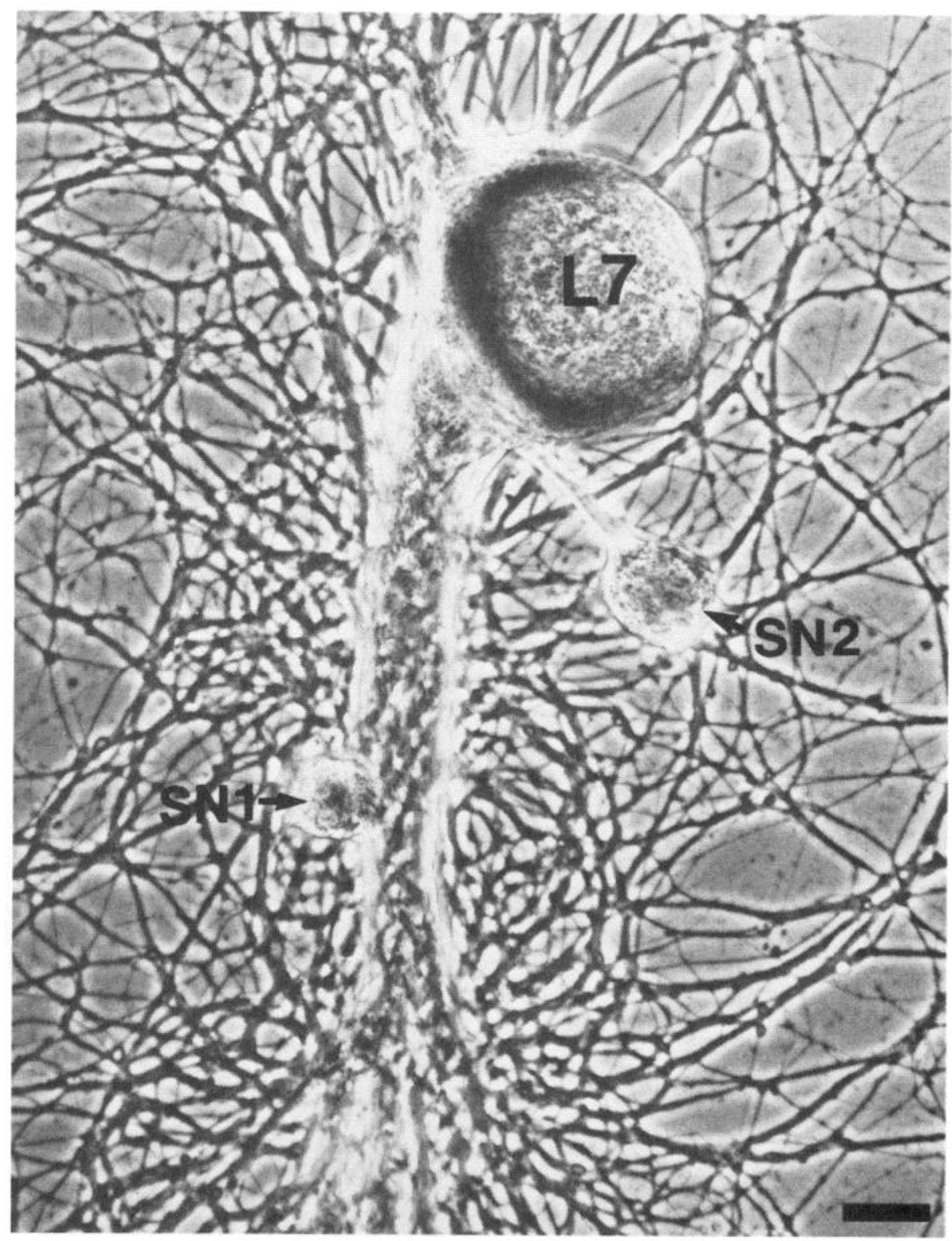

by homosynaptic stimulation (Gingrich and Byrne, 1985; Hochner et al., 1986a, b). We first compared the facilitation evoked by 5 -HT to that of SCP on sensorimotor synapses that had not undergone any depression by low frequency stimulation of the sensory cells (Fig. 2). We then compared the effects of the 2 transmitters after the synapse had first been depressed by homosynaptic stimulation (Fig. 3).

Following a single test stimulus to the sensory cell, a brief 1-2 sec application of either 5-HT $(N=5)$ or SCP $(N=5)$ evoked a significant enhancement in the amplitude of the EPSP $\left(F_{3,16}\right.$ $=15.405, p<0.001$ for treatment; $F_{9.48}=7.196, p<0.001$ for time-treatment interaction). This heterosynaptic facilitation was short-lived (Fig. 2A). Both 5-HT and SCP facilitated the EPSP at $1 \mathrm{~min}$ after treatment; $131 \% \pm 8$ for $5-\mathrm{HT}\left(t_{48}=9.061, p<\right.$ $0.001)$, and $125 \% \pm 2$ for SCP $\left(t_{48}=7.959, p<0.001\right)$ compared to control level of $86 \% \pm 5(N=5)$. After $10 \mathrm{~min}$, both 5-HT and SCP treatments were not different than controls $\left(t_{48}=1.714\right.$, $p>0.05$ and $t_{48}=1.632, p>0.1$, respectively).

We next examined the effects of 5-HT and SCP on sensori- motor synapses that were depressed by at least $75 \%$ from their initial level with low frequency stimulation of the sensory cell (Fig. 3); a situation that is comparable to that occurring in the intact animal with dishabituation. A 1-2 sec application of 5-HT evoked a significant facilitation of $338 \% \pm 45(N=9, t=4.718$, $p<0.01$; Dunnett's $t$-test, 2-tailed) compared to controls, $96 \%$ $\pm 2(N=5)$. By contrast, SCP application evoked little facilitation of $108 \% \pm 13(N=10)$ which was not significantly different from control $(t=0.236)$. Preliminary evidence suggests that the failure of SCP to evoke facilitation under these conditions is not due to an activation of some inhibitory process when sensorimotor synapses are depressed by homosynaptic stimulation. Simultaneous application of SCP $(50 \mu \mathrm{M})$ and 5-HT $(25 \mu \mathrm{M})$ produced a facilitation of $387 \% \pm 29(N=3)$.

The failure of SCP to facilitate depressed sensorimotor synapses may result from its inability to increase cAMP to a critical level within the sensory cell terminals necessary for initiating the transmitter mobilization process required to facilitate a depressed synapse (Abrams et al., 1984; Braha et al., 1990). To 
A

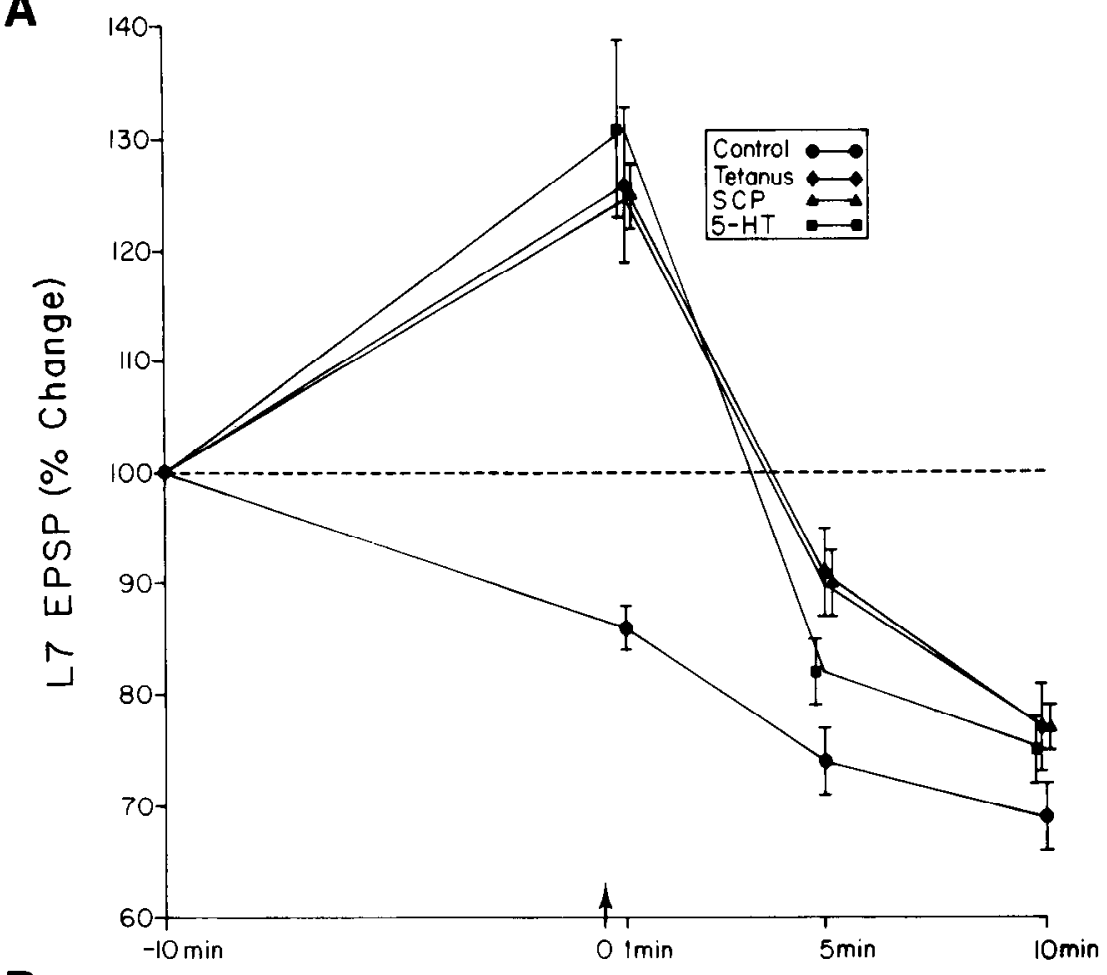

B
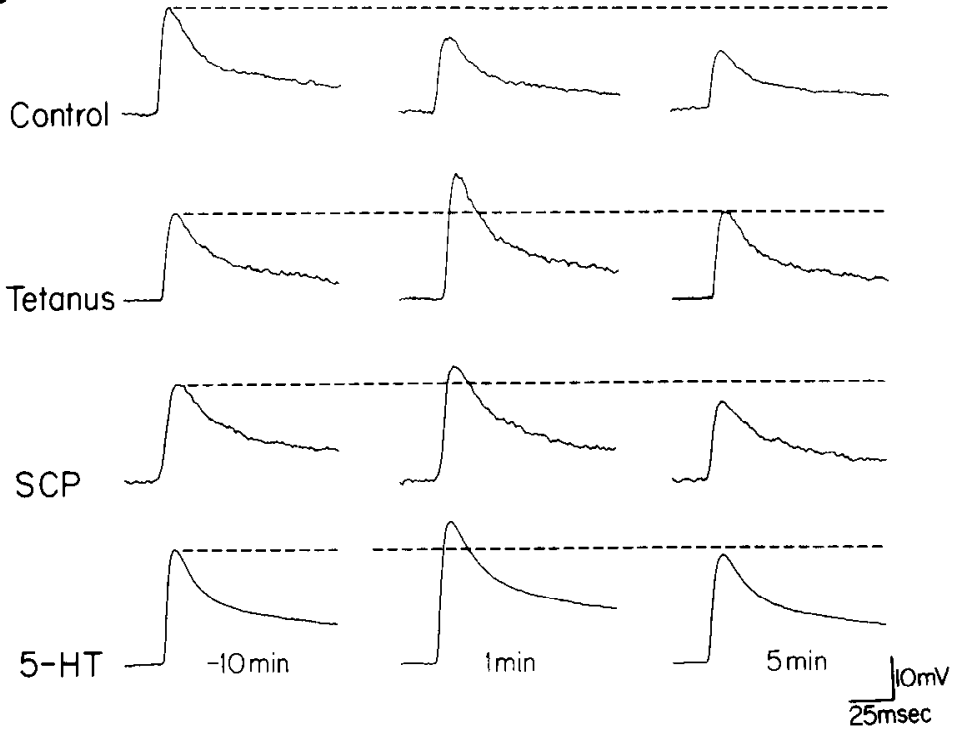

Figure 2. Short-term facilitation of a nondepressed synapse by 5-HT, SCP, and tetanus. $A$, Each point is the mean percent change \pm SEM in the amplitude of the EPSP normalized to the initial amplitude $(-10 \mathrm{~min})$ for each culture (1 sensorimotor connection). Note that the amplitude of the EPSP in control cultures decreased with each stimulus, which is characteristic of homosynaptic depression. A 2-factor overall analysis of variance indicated a difference with treatment (see Materials and Methods and Results). A comparison of the means at each time point indicated that all 3 treatments were significantly different than control $1 \mathrm{~min}$ after treatments, and not significantly different than control at $10 \mathrm{~min}$ (see Results). $B$, Examples of facilitation evoked by 5-HT, SCP, and tetanus compared to the depression evoked with control stimulation. test this possibility, we examined the facilitation of depressed synapses by SCP in the presence of a phosphodiesterase inhibitor IBMX (Fig. 3). As previously reported (Schacher et al., 1988), IBMX alone did not affect nondepressed synapses, nor did it alter the rate of homosynaptic depression. The same number of stimuli to the sensory cells depressed the amplitude of the EPSP to below $75 \%$ of the initial value when IBMX was present as non-IBMX treated cultures. Application of SCP in the presence of IBMX $(N=6)$ now evoked a significant facilitation of $274 \% \pm 51(t=3.197, p<0.05$; Dunnett's $t$-test, 2 -tailed). Facilitation of the EPSP amplitude of $235 \% \pm 29(N$ = 3) was evoked by SCP in the presence of another phosphodiesterase inhibitor (100 $\mu \mathrm{M}$ RO 20-1 724; Hoffmann-La Roche, Nutley, NJ). In addition, the effects of IBMX appear to be reversible. One hr after washout of the IBMX and rest, the same depressed connections that were facilitated in the presence of IBMX $(N=3)$ failed to facilitate with SCP alone application $(105 \% \pm 9)$.

\section{5-HT selectivity evokes long-term facilitation of sensorimotor synapses}

We had previously demonstrated (Montarolo et al., 1986; Dale et al., 1988) that repeated 5 min applications of 5-HT produced a significant enhancement of the L7 EPSP amplitude when the connections were reexamined $24 \mathrm{hr}$ later. We have confirmed these results using, instead of 5-min applications, the brief 1-2 sec puffs described above in the experiments on short-term facilitation. The brief applications of 5-HT evoked a significant 
A

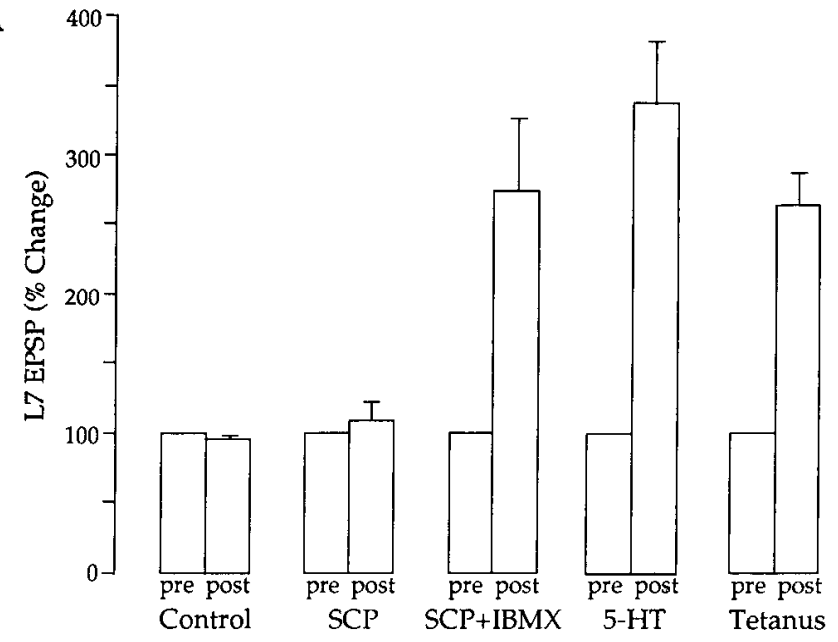

B
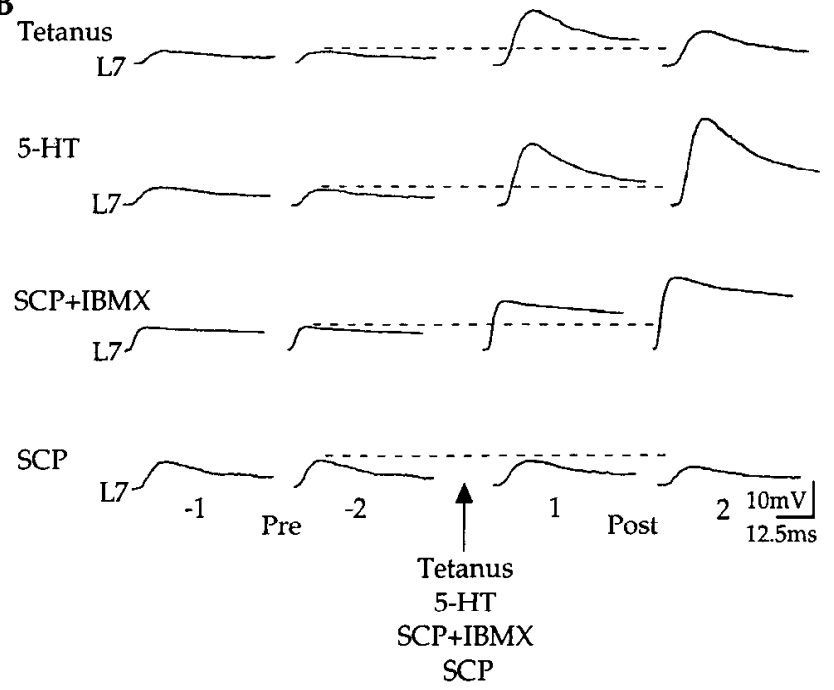

Figure 3. SCP fails to facilitate a synapse depressed by $75 \%$ with homosynaptic depression. $A$, Each bar is the mean percent change \pm SEM in the average amplitude of the first 2 EPSPs evoked in $\mathrm{L} 7 \mathrm{mea-}$ sured after control or experimental treatments (Post) normalized for cach culturc (onc sensorimotor connection) to the avcragc of the last 2 depressed EPSPs evoked in L7 before treatments (Pre). A 2-factor analysis of variance (repeated measures) indicated a significant effect with treatment and treatment-test interactions $\left(F_{4,33}=10.669, p<0.001\right)$. Comparisons of the means (Dunnett's $t$-tests; see Materials and Methods and Results) indicated that 5-HT, tetanus, and SCP plus IBMX treatments were significantly different from controls, but SCP alone was not. $B$, Examples of the facilitation in the amplitude of the EPSP evoked in L7 following tetanus, application of 5-HT, and application of SCP in the presence of IBMX, but not application of SCP alone.

enhancement ( $t=4.468, p<0.01$; Dunnett's $t$-test, 2-tailed) of $158 \% \pm 11(N=6)$ compared to $104 \% \pm 6(N=6)$ for control (Fig. 4). By contrast, repeated applications of SCP failed to evoke a significant change in the EPSP after $24 \mathrm{hr} ; 107 \% \pm 10(N=$ $6 ; t=0.249$ ). The failure of SCP to cvokc a long-term change apparently was not due to desensitization caused by the repeated applications. We examined the short-term facilitation $(N=2$ cultures) evoked with each SCP application given at 20-min intervals. Each application of SCP was capable of evoking a short-term facilitation (range of 118-128\%).

To test the idea that the failure of SCP to evoke a long-term change was due to its inability to increase cAMP to some critical level, we examined the long-term consequences of SCP appli-

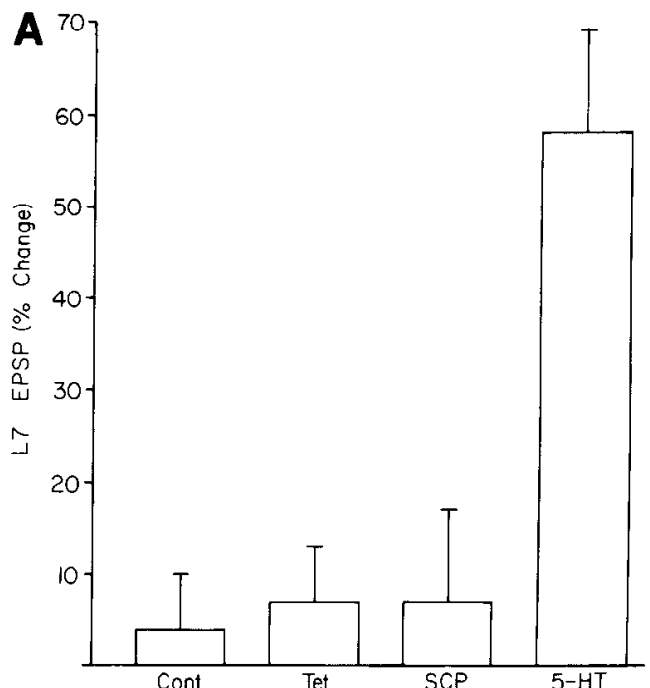

B
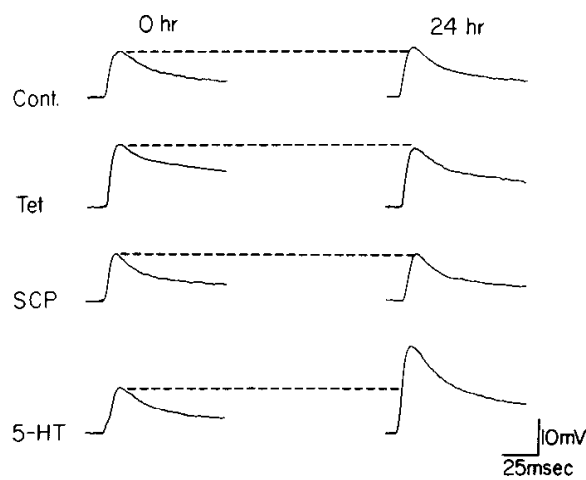

Figure 4. 5-HT applications selectively evoke long-term facilitation. $A$, The height of each bar is the mean percent change \pm SEM in the amplitude of the EPSP evoked in L7 when retested $24 \mathrm{hr}$ after treatment. Each culture counted as 1 sample. A 1-factor analysis of variance indicated a difference with treatment $\mathrm{F}_{3,23}=9.304 ; p<0.001$ ). A comparison of the means (Dunnett's $t$-test; see Results) indicated that 5-HT treatment significantly increased the EPSP relative to control, while tetanus and SCP treatments were not significantly different than controls. B. Examples of the facilitation in the amplitude of the EPSP 24 $\mathrm{hr}$ following repeated applications of 5-HT, but not following control, tctanus, and SCP treatments.

cations in the presence of IBMX (Fig. 5A). SCP applications in the presence of IBMX $(N=6)$ now evoked a significant $\left(t_{10}=\right.$ $3.314, p<0.01$; unpaired $t$-test, 2 -tailed) increase of $135 \% \pm$ 7 compared to $102 \% \pm 6(N=6)$ for cultures treated with IBMX alone.

Tetanic stimulation of the sensory cell evokes short-but not long-term facilitation

Previous studies comparing the effects of homosynaptic and heterosynaptic mechanisms on depression of the sensorimotor synapse indicated that long-term inhibition of this synapse may require the actions of specific heterosynaptic pathways. Although sensory synapses can be depressed for a short duration by application of either the neuropeptide FMRFamide or dopamine, or by homosynaptic depression (low frequency stimulation of the sensory cell), long-term depression is evoked selectively by applications of FMR Famide (Montarolo et al., 1988). In the intact nervous system, tetanic stimulation of the sensory 
A1

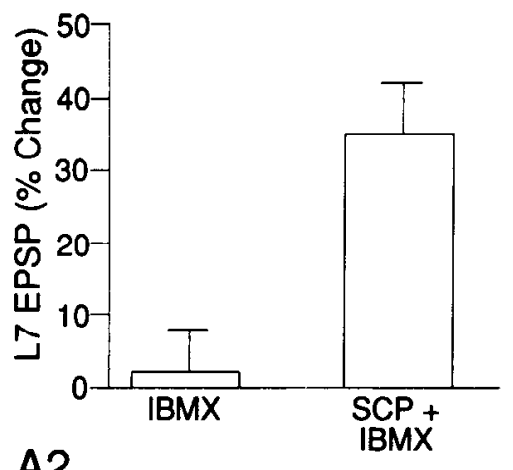

A2
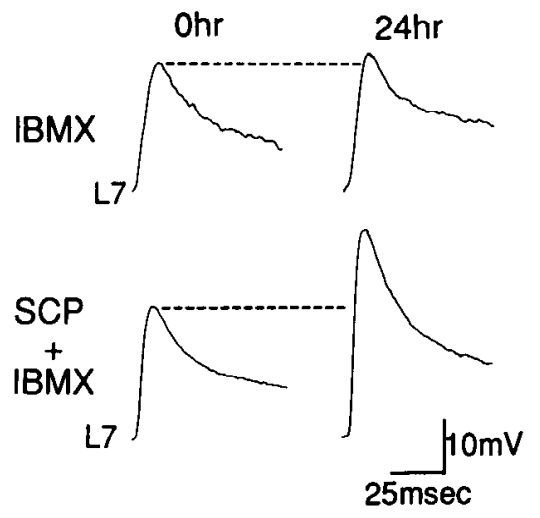

B1
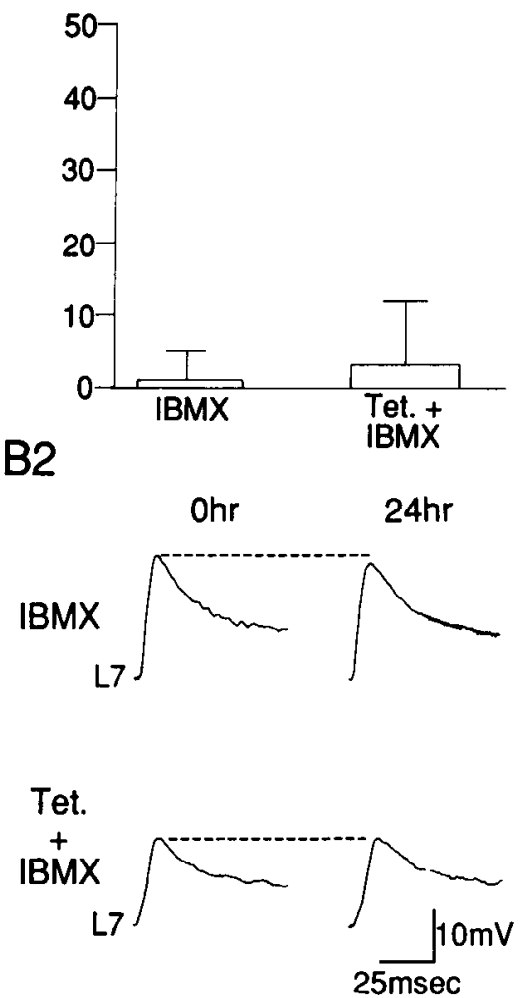

Figure 5. SCP applications, but not tetanus, in the presence of IBMX evoke long-term facilitation. The height of each bar is the mean percent change \pm SEM in the amplitude of the EPSP evoked in $\mathrm{L} 7$ when retested $24 \mathrm{hr}$ after treatments. Each culture counted as 1 sample, $A 1, \mathrm{SCP}$ applications in the continuous presence of IBMX significantly increased the EPSP compared to treatment with IBMX alone (see Results). A2, Examples of the facilitation in the EPSP evoked in L7 $24 \mathrm{hr}$ following applications of SCP in the presence of IBMX, but not following treatment with IBMX alone. B1, Repeated tetani to the sensory cells in the presence of IBMX evoked little long-term change and was not significantly different than treatment with IBMX alone (see Results). $B 2$, Examples of the absence of a long-term facilitation $24 \mathrm{hr}$ following repeated tetani in the presence of IBMX or treatment with IBMX alone. cells can also facilitate sensorimotor synapses for a short duration (Walters and Byrne, 1984, 1985; Clarke and Kandel, 1984). We therefore compared the consequences of this homosynaptic pathway on short- and long-term facilitation of the sensorimotor synapses to those evoked by the neuromodulators.

Tetanic stimulation of the sensory cell, as 5-HT, evokes facilitation of both nondepressed and depressed synapses (Figs. $2,3)$. One min after tetanus was given to a sensory cell that received only a single stimulus, the EPSP amplitude was significantly enhanced to $126 \% \pm 7\left(N=5 ; t_{48}=8.163, p<0.001\right)$ compared to controls (Fig. $2 A$ ). The facilitation was short-lived: by $10 \mathrm{~min}$, treated cells were no longer significantly different from controls $\left(t_{48}=1.632, p>0.1\right)$. Tetanic stimulation also evoked a significant facilitation of depressed synapses (Fig. 3) to $264 \% \pm 22(N=8 ; t=3.207, p<0.05$; Dunnett's $t$-test, 2-tailed) compared to controls (Fig. $3 A$ ).

Although tetanus can evoke short-term enhancement, repeated tetanic stimulation failed to evoke a significant longterm change (Fig. 4). The EPSP amplitudes reexamined $24 \mathrm{hr}$ after repeated tetanic stimulation were not significantly increased, $107 \% \pm 6(N=6 ; t=0.235$; Dunnett's $t$-test, 2-tailed) compared to controls (Fig. $4 A$ ). The failure to evoke a longlasting change was not due to synapse fatigue during the tetani. The amplitude of the EPSP evoked with the first stimulus of the final tetanus was increased significantly by $119 \% \pm 5(N=$ $4 ; t_{3}=3.265, p<0.05$; paired t-test, 2-tailed) compared to the FPSP amplitude measured before tetanic stimulation. In addition, treatment with IBMX, which resulted in long-term facilitation with SCP applications, dud not alter the long-term consequences of tetanic stimulation (Fig. $5 B$ ). Repeated tetanic stimulation in the presence of IBMX evoked little long-term change in the amplitude of the EPSP, $103 \% \pm 9(N=6)$, compared to IBMX alone cultures, $101 \% \pm 4\left(N=6 ; t_{10}=0.202\right)$.
Tetanic stimulation in the presence of IBMX did not cause the connections to fatiguc, since the amplitude of the first EPSP evoked during the last tetanus was significantly enhanced by $123 \% \pm 8\left(N=6 ; t_{s}=3.015, p<0.05\right.$; paired $t$-test, 2-tailed $)$ compared to the EPSP evoked before the first tetanus.

\section{Discussion}

Multiple modulatory pathways produce short-term facilitation of sensorimotor synapses of Aplysia

Our study confirms previous work indicating that 5-HT plays a critical role in facilitating the synapses between the sensory and motor cells, either when the synapses are not depressed or when they are depressed as is the case in behavioral sensitization or dishabituation, respectively. At least 2 processes initiated by 5-HT contribute to the increase in transmitter release at sensorimotor synapses during short-term facilitation. One process involves broadening of the action potential in the sensory cell through closure of a serotonin-sensitive potassium channel by cAMP-dependent phosphorylation leading to the increase in calcium entry (Castellucci et al., 1982; Klein et al., 1982; Siegelbaum et al., 1982). This process contributes as significantly when the synapse is not depressed as would occur with sensitization of the reflex (Hochner et al., 1986a, b). Broadening of the action potential is not sufficient however, to enhance a synapse that has been depressed with homosynaptic depression. A second process, independent of spike broadening, is required to mobilize transmitter release (Gingrich and Byrne, 1985; Hochner et al., 1986a, b; Dale and Kandel, 1990). Recent evidence suggests that this second process can be initiated either by increased levels of cAMP or by activation of C-kinase (Braha et al., 1990). The role of 5-HT in this second process is supported by the findings that application of 5-HT is known to increase levels of cAMP (Bernier et al., 1982; Occor and Byrne, 1985) 
and cAMP-dependent phosphorylation (Sweatt and Kandel, 1989), and can also translocate C-kinase from the inactive soluble form to the active membrane-bound form (Saktor and Schwartz, 1990).

The ability of SCP to facilitate nondepressed sensorimotor synapses is consistent with the ability of SCP to increase levels of cAMP in sensory cells, thereby closing serotonin-sensitive potassium channcls as wcll as broadening the action potentials (Abrams et al., 1984; Occor and Byrne, 1985). The failure of SCP, however, to significantly enhance depressed synapses in culture or in the intact nervous system (Pieroni and Byrne, 1989) indicates that SCP fails to activate the second process involving transmitter mobilization and thus does not by itself contribute to facilitation associated with dishabituation. Because SCP receptors and the associated signal transduction system are distinct from that of 5-HT (Abrams et al., 1984; Occor and Byrne, 1986), there are at least 2 explanations for the failure of SCP to facilitate depressed sensorimotor synapses. First, the distribution of SCP receptors on sensory cells may differ from that of 5-HT such that it fails to enhance sufficiently cAMP levels within the terminals of the sensory cells. Isolated growth cones of sensory cells contain receptors for $5-\mathrm{HT}$ and the appropriate intracellular machinery for signal transduction. (Belardetti et al., 1986). If fewer SCP receptors are present at the terminals, SCP might fail to facilitate because high levels of cAMP in the terminals may be required for transmitter mobilization (Braha et al., 1990). When SCP is now applied in the presence of phosphodiesterase inhibitors, or when applied together with 5-HT, cAMP levels within the terminals could reach the levels required for transmitter mobilization.

A second explanation for the failure of SCP to facilitate depressed synapses is that unlike 5-HT (Saktor and Schwartz, 1990), SCP may not activate the C-kinase system in sensory cells. In support of the role of $\mathrm{C}$-kinase in facilitating depressed synapses are the findings that phorbol esters can mimic the actions of 5-HT in facilitating depressed synapses. Moreover, the kinase inhibitor $\mathrm{H} 7$, which in Aplysia appears to be more selective for C-kinase (Conn et al., 1989), becomes progressively more effective in blocking 5-HT facilitation as the sensorimotor synapse is depressed to lower levels (Braha et al., 1990). The ability of 5-HT to facilitate a depressed synapse may therefore involve the coactivation of 2 second-messenger systems: the A-kinase and C-kinase systems. The synergistic effects on synapse plasticity of activating multiple second-messenger systems have also been implicated in long-term potentiation in the hippocampus (Lynch and Baudry, 1984; Malenka et al., 1986, 1989; Manilow et al., 1989; Williams et al., 1989), and associativc conditioning in Aplysia (Hawkins et al, 1983; Walters and Byrne, 1983, 1985; Occor et al., 1985) and Hermissenda (Acosta-Urquidi et al., 1984; Farley and Auerbach, 1986). In contrast, SCP might not be able to facilitate depressed synapses because it activates only 1 of the 2 second-messenger systems.

Our results also confirm previous work on posttetanic potentiation of sensory neuron synapses in the intact nervous system of Aplysia (Walters and Byrne, 1984, 1985; Clarke and Kandel, 1984). Posttetanic potentiation is thought to be mediated in part by the increase in intracellular calcium within the terminals, thereby facilitating the release of transmitter with subsequent action potentials (Katz and Miledi, 1968; Rahamimoff, 1968; Kretz et al., 1982; Connor et al., 1986). Our results further indicate that this increase in calcium can serve as another mechanism in facilitating both nondepressed and depressed synapses.
In both cases, the increase in intracellular calcium may activate calcium-dependent processes affecting cytoskeletal elements or other substrate proteins involved with the transmitter release process or mobilization (Llinas et al., 1985; Rasmussen and Means, 1989; Kennedy, 1990).

\section{Specific modulatory pathway evokes long-term facilitation of sensorimotor synapses of Aplysia}

Although a single brief application of 5-HT or SCP evokes comparable short-term enhancement of sensorimotor connections, only repeated brief applications of 5-HT produce a long-term change. These findings parallel results reported for long-term depression of this synapse produced by repeated application of the neuropeptide FMRFamide or dopamine (Montarolo et al., 1988). A single application of either inhibitory neurotransmitter evoked comparable short-term changes in the synapse, but only FMRFamide produced a long-term change. The failure to produce a long-term change with repeated tetanic stimulation, where a single tetanus evokes short-lasting facilitation, also parallels the inability to produce long-term depression with repeated lowfrequency stimulation of the sensory cells (Montarolo et al., 1988). Thus, short-lasting changes in this synapse may be evoked by activation of different heterosynaptic and homosynaptic pathways, but long-term facilitation or depression may require specifically 5-HT or FMRFamide, respectively.

The failure of SCP to evoke a long-term change, unless it was applied in the presence of the phosphodiesterase inhibitor IBMX, indicates that repeated SCP applications alone fail to induce a change in the cells that is necessary for the long-term facilitation. Previous studies on the intact nervous system and on the in vitro synapse suggest that $\mathrm{CAMP}$, persistant CAMP-dependent phosphorylation of substrate proteins, persistent activation of A-kinase, and cAMP induction of gene expression are critical for the expression of long-term facilitation and other changes associated with long-term behavioral sensitization (Greenberg et al., 1987; Schacher et al., 1988; Sholz and Byrne, 1988; Sweatt and Kandel, 1989; Dash et al., 1990). Thus, although SCP can enhance levels of cAMP sufficiently to evoke a short-lasting facilitation of nondepressed synapses, it does not sufficiently enhance CAMP levels and the cAMP-dependent processes required to evoke a long-term change. A critical level of cAMP elevation may also underlie long-term facilitation of crayfish neuromuscular junctions (Dixon and Atwood, 1989). This critical level can be achieved by 5 -HT alone, or when the actions of SCP on CAMP levels are enhanced by the presence of IBMX. This difference between 5-HT and SCP may arise from an intrinsic difference in the transduction of the repeated receptor activation with the cAMP cascade. Alternatively, SCP may fail to activate sufficiently the A-kinase system for the long-term change because unlike 5-HT, it may not activate the C-kinase system. According to this latter scheme, the ability of repeated 5-HT applications to evoke repeated and simultaneous activation of both the A-kinase and the C-kinase systems may result in a sufficient enhancement of cAMP levels and/or A-kinase activity that is necessary for long-term facilitation. With appropriate pharmacological tools, it may be possible to test these alternative mechanisms.

\section{References}

Abrams TW, Castellucci VF, Camardo JS, Kandel ER, Lloyd P (1984) Two endogenous neuropeptides modulate the gill- and siphon-withdrawal reflex in Aplysia by presynaptic facilitation involving cAMP- 
dependent closure of a serotonin-sensitive potassium channel. Proc Natl Acad Sci USA 81:7956-7960.

Acosta-Urquidi J, Alkon DL, Neary JT (1984) Calcium-dependent protein kinase injection in a photoreceptor mimics biophysical effects of associative learning. Science 224:1254-1257.

Bailey CH, Chen M (1983) Morphological basis of long-term habituation and sensitization in Aplysia. Science 220:91-93.

Bailey CH, Chen M (1988a) Long-term memory in Aplysia modulates the total number of varicosities of single identified sensory neurons. Proc Natl Acad Sci USA 85:2373-2377.

Bailey CH, Chen M (1988b) Long-term sensitization in Aplysia increases the number of presynaptic contacts onto the identified gill motor neuron L7. Proc Natl Acad Sci USA 85:9356-9359.

Belardetti F, Schacher S, Kandel ER, Siegelbaum SA (1986) The growth cones of Aplysia sensory neurons: modulation by serotonin of action potential duration and single potassium channel currents. Proc Natl Acad Sci USA 83:7094-7098.

Bemier L, Castellucci VF, Kandel ER, Schwartz JH (1982) Facilitatory transmitter causes a selective and prolonged increase in adenine 3': $5^{\prime}$-monophosphate in sensory neurons mediating the gill and siphon withdrawal reflex in Aplysia. J Neurosci 2:1682-1691.

Braha O, Dale N, Hochner B, Klein M, Abrams TW, Kandel ER (1990) Second messengers involved in the two processes of presynaptic facilitation that contribute to sensitization and dishabituation in Aplysia sensory neurons. Proc Natl Acad Sci USA 87:2040-2044.

Brunelli M, Castellucci VF, Kandel ER (1976) Synaptic facilitation and behavioral sensitization in Aplysia: possible role of serotonin and cAMP. Science 194:1178-1181.

Carew TJ, Castellucci VF, Kandel ER (1971) An analysis of dishabituation and sensitization of the gill-withdrawal reflex in Aplysia. Int J Neurosci 2:79-98.

Castellucci VF, Kandel ER (1976) Presynaptic facilitation as a mechanism for behavioral sensitization in Aplysia. Science 194:1176-1178.

Castellucci VF, Pinsker H, Kupfermann I, Kandel ER (1970) Neuronal mechanisms of habituation and dishabituation of the gill-withdrawal reflex in Aplysia. Science 167:1745-1748.

Castellucci VF, Kandel ER, Schwartz JH, Wilson FD, Nairn AC, Greengard P (1980) Intracellular injection of the catalytic subunit of cyclic AMP-dependent protein kinase simulates facilitation of transmitter release underlying behavioral sensitization in Aplysia. Proc Natl Acad Sci USA 77:7492-7496.

Castellucci VF, Nairn A, Greengard P, Schwartz JH, Kandel ER (1982) Inhibitor of adenosine $3^{\prime}: 5^{\prime}$-monophosphate-dependent protein kinase blocks presynaptic facilitation in Aplysia. J Neurosci 2:16731681.

Clark GA, Kandel ER (1984) Branch-specific heterosynaptic facilitation in Aplysia siphon sensory cells. Proc Natl Acad Sci USA 81: $2577-2581$.

Conn PJ, Strong JA, Azhderian EM, Nairn AC, Greengard P, Kaczmarek LK (1989) Protein kinase inhibitors selectively block phorbol ester- or forskolin-induced changes in excitability of Aplysia neurons. J Neurosci 9:473-479.

Connor JA, Kretz R, Shapiro E (1986) Calcium levels in a presynaptic neurone of Aplysia under conditions that modulate transmitter release. J Physiol (Lond) 375:625-642.

Dale N, Kandel ER (1990) Facilitatory and inhibitory transmitters modulate spontaneous transmitter release at cultured Aplysia sensorimotor synapses. J Physiol (Lond) 421:203-222.

Dale N, Schacher S, Kandel ER (1988) Long-term facilitation in Aplysia involves increase in transmitter release. Science 239:282-285.

Dash PK, Hochner B, Kandel ER (1990) Injection of the cyclic AMP responsive element into the nucleus of Aplysia sensory neurons blocks long-term facilitation. Nature 345:718-721.

Dixon D, Atwood HL (1989) Adenylate cyclase system is essential for long-term facilitation at the crayfish neuromuscular junction. J Neurosci 9:4246-4252.

Farley J, Auerbach S (1986) Protein kinase C activation induces conductance changes in Hermissenda photoreceptors like those seen in associative learning. Nature 319:220-223.

Frost WN, Castellucci VF, Hawkins RD, Kandel ER (1985) The monosynaptic connections from the sensory neurons participate in the storage of long-term memory for sensitization of the gill- and siphon-withdrawal reflex in Aplysia. Proc Natl Acad Sci USA 82: 8266-8269.

Gingrich KJ, Byrne JH (1985) Simulation of synaptic depression, posttetanic potentiation and presynaptic facilitation of synaptic potentials from sensory neurons mediating gill-withdrawal reflex in Aplysia. J Neurophysiol 53:652-669.

Glanzman DL, Mackey SL, Hawkins RD, Dyke AM, Lloyd PE, Kandel ER (1989) Depletion of serotonin in the nervous system of Aplysia reduces the behavioral enhancement of gill withdrawal as well as the heterosynaptic facilitation produced by tail shock. J Neurosci 9:42004213.

Glanzman DL, Kandel ER, Schacher S (1990) Target-dependent structural changes accompanying long-term synaptic facilitation in Aplysia neurons. Science (in press).

Greenberg SM, Castellucci VF, Bayley H, Schwartz JH (1987) A molecular mechanism for long-term sensitization in Aplysia. Nature 329: $62-65$.

Hawkins RD (1989) Localization of potential serotonergic facilitator neurons in Aplysia by glyoxilic acid histofluorescence combined with retrograde fluorescent labeling. J Neurosci 9:4214-4226.

Hawkins RD, Schacher S (1989) Identified facilitator neurons L29 and L28 are excited by cutaneous stimuli used in dishabituation, sensitization, and classical conditioning of Aplysia. J Neurosci 9:42364245 .

Hawkins RD, Castellucci VF, Kandel ER (1981) Interneurons involved in mediation and modulation of gill-withdrawal reflex in Aplysia. II. Identified neurons produce heterosynaptic facilitation contributing to behavioral sensitization. J Neurophysiol 45:315-326.

Hawkins RD, Abrams TW, Carcw TJ, Kandel ER (1983) A cellular mechanism of classical conditioning in Aplysia: activity-dependent amplification of presynaptic facilitation. Science 219:400-405.

Hochner B, Klein M, Schacher S, Kandel ER (1986a) Action-potential duration and the modulation of transmitter release from the sensory neurons of Aplysia in presynaptic facilitation and behavioral sensitization. Proc Natl Acad Sci USA 83:8410-8414.

Hochner B, Klein M, Schacher S, Kandel ER (1986b) Additional component in the cellular mechanism of presynaptic facilitation contributes to behavioral dishabituation in Aplysia. Proc Natl Acad Sci USA 83:8794-8798.

Kat $\mathrm{B}$, Miledi R (1968) The role of calcium in neuromuscular facilitation. J Physiol (Lond) 195:481-492.

Kennedy MB (1990) Regulation of synaptic transmission in the central nervous system: long-term potentiation. Cell 59:777-787.

Klein M, Kandel ER (1978) Presynaptic modulation of voltage-dependent calcium current: mechanism for behavioral sensitization in Aplysia californica. Proc Natl Acad Sci USA 75:3512-3516.

Klein M, Camardo J, Kandel ER (1982) Serotonin modulates a specific potassium current in the sensory ncurons that show presynaptic facilitation in Aplysia. Proc Natl Acad Sci USA 79:5713-5717.

Klein M, Hochner B, Kandel ER (1986) Facilitatory transmitters and cAMP can modulate accommodation as well as transmitter release in Aplysia sensory neurons: evidence for parallel processing in a single cell. Proc Natl Acad Sci USA 83:7994-7998.

Kretz R, Shapiro E, Kandel ER (1982) Posttetanic potentiation at an identified synapse of Aplysia is correlated with a calcium-activated potassium current in the presynaptic neuron: evidence for calcium accumulation. Proc Natl Acad Sci USA 79:5430-5434.

Llinas R, McGuiness TL, Leonard CS, Sugimori M, Greengard P (1985) Intraterminal injection of synapsin I or calcium/calmodulin dependent protein kinase II alters neurotransmitter release at the squid giant synapse. Proc Natl Acad Sci USA 77:7039-7043.

Lynch G, Baudry M (1984) The biochemistry of memory: a new and specific hypothesis. Science 224:1057-1063.

Mackey SI, Kandel ER, Hawkins RD (1989) Identified serotonergic neurons LCB1 and RCB1 in the cerebral ganglia of Aplysia produce presynaptic facilitation of siphon sensory neurons. J Neurosci 9:42274235.

Malenka RC, Madison DV, Nicoll RA (1986) Potentiation of synaptic transmission in hippocampus by phorbol esters. Nature 321:175-177.

Malenka RC, Kauer JA, Perkel DJ, Mauk MD, Kelly PT, Nicholl RA, Waxman MN (1989) An essential role for postsynaptic calmodulin and protein kinase activity in long-term potentiation. Nature 340: 554-557.

Malinow R, Schulman H, Tsien RW (1989) Inhibition of postsynaptic PKC or CaMKII blocks induction but not expression of LTP. Science 245:862-866.

Marcus EA, Nolen TG, Rankin CH, Carew TJ (1988) Behavioral 
dissociation of dishabituation, sensitization, and inhibition in Aplysia. Science 241:210-213.

Montarolo PG, Goelet P, Castellucci VF, Morgan J, Kandel ER, Schacher $S$ (1986) A critical time window for macromolecular synthesis in long-term heterosynaptic facilitation in Aplysia. Science 234:12491254.

Montarolo PG, Kandel ER, Schacher S (1988) Long-term heterosynaptic inhibition in Aplysia. Nature 333:171-174.

Occor KA, Byrne JH (1985) Membrane responses and changes in cAMP levels in Aplysia sensory neurons produced by serotonin, tryptamine, FMRFamide and small cardioactive peptide (SCPb). Neurosci Lett 55:113-118.

Occor KA, Byrne JH (1986) Evidence for separate receptors that mediate parallel effects of serotonin and small cardioactive peptide $(\mathrm{SCPb})$ on adenylate cyclase in Aplysia californica. Neurosci Lett 70:283288.

Occor KA, Walters ET, Byrne JH (1985) Associative conditioning analog selectivity increases cAMP levels of tail sensory neurons in Aplysia. Proc Natl Acad Sci USA 82:2548-2552.

Pieroni JP, Byrne JH (1989) Differential effects of serotonin, SCPb and FMRFamide on processes contributing to presynaptic facilitation in sensory neurons of Aplysia. Soc Neurosci Abstr 15:1284.

Pinsker IIM, Kupfermann I, Castellucci VF, Kandel ER (1970) $\mathrm{Ha}-$ bituation and dishabituation of the gill-withdrawal reflex in Aplysia. Science 167:1740-1742.

Pinsker HM, Hening WA, Carew TJ, Kandel ER (1973) Long-term sensitization of a defensive withdrawal reflex in Aplysia. Science 182: 1039-1042.

Rahamimoff $R$ (1968) The dual effect of calcium ions on neuromuscular facilitation. J Physiol (Lond) 195:471-480.

Rasmussen CD, Means AR (1989) Calmodulin, cell growth and gene expression. Trends Neurosci 12:433-437.

Rayport SG, Schacher S (1986) Synaptic plasticity in vitro: cell culture of identified Aplysia neurons mediating short-term habituation and sensitization. J Neurosci 6:759-763.
Saktor TC, Schwartz JH (1990) Sensitizing stimuli cause translocation of protein kinase C in Aplysia sensory neurons. Proc Natl Acad Sci USA 87:2036-2039.

Schacher S (1985) Differential synapse formation and neurite outgrowth at two branches of the metecerebral cell of Aplysia in dissociated cell culture. J Neurosci 5:2028-2034.

Schacher S, Montarolo PG (1988) Serotonin selectively produces longterm facilitation of Aplysia sensorimotor synapses in culture. Soc Neurosci Abstr 14:909.

Schacher S, Proshansky E (1983) Neurite regeneration by Aplysia neurons in dissociated cell culture: modulation by Aplysia hemolymph and the presence of the initial axon segment. J Neurosci 3:2403-2413.

Schacher S, Castellucci VF, Kandel ER (1988) cAMP evokes longterm facilitation in Aplysia sensory neurons that requires new protein synthesis. Science 240:1667-1669.

Scholz KP, Byrne JH (1988) Intracellular injection of cyclic AMP induces a long-term reduction of neuronal potassium currents. Science 240:1664-1667.

Siegelbaum SA, Camardo JS, Kandel ER (1982) Serotonin and cAMP close single potassium channels in Aplysia sensory neurones. Nature 299:413-417.

Sweatt JD, Kandel ER (1989) Persistent and transcriptionally dependent increase in protein phosphorylation in long-term facilitation of Aplysia sensory neurons. Nature 339:51-54.

Walters ET, Byrne JH (1983) Associative conditioning of single sensory neurons suggests a cellular mechanism for learning. Science 219: 405-408.

Walters ET, Byrne JH (1984) Posttetanic potentiation in Aplysia sensory neurons. Brain Res 293:377-380.

Walters ET, Byrne JH (1985) Long-term enhancement produced by activity dependent modulation of Aplysia sensory neurons. J Neurosci $5: 662-672$.

Williams JH, Errington ML, Lynch MA, Bliss TVP (1989) Arachidonic acid induces a long-term activity-dependent enhancement of synaptic transmission in the hippocampus. Nature 341:739-742. 